\author{
Asian Journal of \\ Medical and Biological Research \\ ISSN 2411-4472 (Print) 2412-5571 (Online) \\ www.ebupress.com/journal/ajmbr
}

\title{
Article \\ Knowledge and attitude on cardiovascular diseases among women in selected areas of Dhaka city
}

\author{
Kazi Md. Obaydul Hoq ${ }^{1 *}$, Marufa Jerin², Md. Shafayet Uddin ${ }^{3}$ and Zahid Hasan Khan ${ }^{4}$ \\ ${ }^{1}$ Field Research Officer, Infectious Diseases Division, International Centre for Diarrhoeal Disease Research \\ Bangladesh (icddr,b), Mohakhali, Dhaka 1216, Bangladesh \\ ${ }^{2}$ Medical Officer, Surjer Hasi Clinic (Swanirvar Bangladesh), Middle Pirerbug, Dhaka 1216, Bangladesh \\ ${ }^{3}$ Field Research Supervisor, Infectious Diseases Division, International Centre for Diarrhoeal Disease Research \\ Bangladesh (icddr,b), Mohakhali, Dhaka 1216, Bangladesh \\ ${ }^{4}$ Medical Officer, Infectious Diseases Division, International Centre for Diarrhoeal Disease Research \\ Bangladesh (icddr,b), Mohakhali, Dhaka 1216, Bangladesh
}

*Corresponding author: Kazi Md. Obaydul Hoq, Field Research Officer, Infectious Diseases Division, International Centre for Diarrhoeal Disease Research Bangladesh (icddr,b), Mohakhali, Dhaka 1216, Bangladesh. E-mail: kobaydul@icddrb.org

Received: 27 November 2017/Accepted: 19 December 2017/ Published: 28 December 2017

\begin{abstract}
Cardiovascular diseases (CVD) are the leading cause of morbidity and mortality not only in Bangladesh but also all over the world. In Bangladesh, Women are more vulnerable group in all socio economic indexes. A cross-sectional study was conducted among 300 women from Dhaka City. Samples were chosen purposively Data were collected by semi structured self administered questionnaire. Questionnaire was based on Likert scale. Data analysis was performed by using Statistical Package for Social Science - 17.0 for windows. 75.4\% respondent were in the age group of 18-35 years (Mean 30.56, Min:18 years and Max: 68 years). Majority ( $89 \%)$ were married \& Muslim (99\%) by religion, half of the participant (49.3\%) were completed only primary education which indicate the poor status of women education in Bangladesh. The family size of most of the respondent (58\%) are 4-6. Very few respondent have large family. It was found that $56.7 \%$ of respondents had good knowledge, 8.3 percent had satisfactory knowledge, $1.7 \%$ had excellent knowledge and the remaining 29 percent had poor knowledge regarding cardiovascular diseases. The study revealed that among the total respondent, $99.7 \%$ women showed negative attitude \& told that they would never involved in smoking. On the other hand $27.7 \%$ women show negative attitude \& told that the take non smoke tobacco. Among women $56.67 \%$ respondent attitude were Moderately Favorable followed by $29 \%$ respondents were Favorable followed. Remaining $14.33 \%$ respondent attitude were favorable attitude. This study revealed that good knowledge as well as positive attitude towards major risk factors of cardiovascular diseases among the women is unsatisfactory. Socio-demographic factors for good knowledge and good knowledge for the development of positive attitude play vital role. The problem of cardiovascular diseases cannot be solved by Government alone. For effective prevention and control of cardiovascular disease, Govt. \& private organization need to make integrated initiative in order to minimize the problem.
\end{abstract}

Keywords: knowledge; attitude; major risk factors; cardiovascular diseases; adolescent

\footnotetext{
1. Introduction

Cardiovascular diseases (CVDs) are a group of disorders of the heart and blood vessels. These are the leading cause of morbidity and mortality worldwide. Cardiovascular disease (CVD) is a general term that describes a disease of the heart or blood vessels. Blood flow to the heart, brain or body can be reduced as the result of a blood clot (thrombosis). Significant advances in our knowledge about interventions to prevent cardiovascular
} 
disease (CVD) have occurred since publication of the first female-specific recommendations for preventive cardiology in 1999 (Mosca et al.,1999). Though in Bangladesh, very few research administering based on women. Some CVD based research we found, but most of the research are implement generally. Despite research-based gains in the treatment of CVD, it remains the leading killer of women in the United States and in most developed areas of the world (Yusuf et al., 2001). Cardiovascular diseases (CVDs) are a group of disorders of the heart and blood vessels. Bangladeshis are having heart attacks at least 10 years earlier than the typical sufferers of the condition in western countries, according to preliminary findings of BRAVE, the largest study of cardiovascular disease ever held in Bangladesh. The findings revealed that the average age among Bangladeshis to have heart attacks was 52 years, with approximately $40 \%$ of all cases occurring in people aged less than 50 years (Manson et al., 2014). These are the leading cause of morbidity and mortality worldwide. (Limbu et al., 2001). The South Asian countries Nepal, India, Pakistan, Sri-Lanka and Bangladesh contribute most to the worldwide CVDs burden. Noncommunicable diseases (NCDs) are the leading causes of death globally, killing more people each year than all other causes combined. Contrary to popular opinion, available data demonstrate that nearly $80 \%$ of NCD deaths occur in low- and middle-income countries. Cardiovascular diseases (CVDs) contribute $48 \%$ towards the deaths due to NCDs in India (Kandpal et al., 2016). Despite their rapid growth and inequitable distribution, much of the human and social impact caused each year by NCDrelated deaths could be averted through well-understood, cost-effective and feasible interventions (Mendis et al., 2014). According to a survey report of the Bangladesh Bureau of Statistics released in June 2015, the prevalence of heart diseases, cancer and arthritis increased sharply since 2000. The incidence of heart diseases rose to 6.59 per thousand in 2014 from 1.6 in 2000, shows the report. As a result individual citizens are compelled to bear an increasing expenditure to access treatments, show the studies conducted by the government's Health Economics Unit. Now, individual citizens have to bear over 63 per cent of their health care expenses, one of the highest in South Asia, according to Bangladesh National Health Accounts. Health expenditures became a huge burden on most of the citizens in Bangladesh. In 2014, the Gross National Income purchasing power parity (PPP) in Bangladesh was US $\$ 3330$. The total government expenditure on health was $3.4 \%$ of total gross domestic product (GDP) in 2008 and per capita total expenditure on health was only US\$15 (Dhillon et al., 2012). Health care expenses pauperized the country's middle income groups. But the affluent groups face no problems as they easily fly to India, Thailand, Singapore, USA, UK and Malaysia to get the needed treatments. Similarly, the common people find the treatment costs of cardiovascular diseases unaffordable. Now, approximately 50 public and private hospitals across the country provide treatment of cardiovascular diseases. But only National Institute of Cardiovascular Diseases in the capital and the Chittagong Medical College Hospital provide cardiac surgery at relatively low costs. So General people able to admitted to the hospital in order to resolve their problem along with affordable cost. Girls and women have less access to resources and opportunities and are subjected to exploitation, violence and abuse. And because these global challenges are complex, demanding and interwoven the solutions have to be connected as well. The little available data suggest that women in rural areas, younger women and girl children with CVD are less likely to receive appropriate management than men.

Cardiovascular disease (CVD) is now a days the leading cause of death for men and women both in the developed and developing countries (WHO, 2004). It was reported that the mortality from CVD was projected to decline in the developed countries from 1970 to 2015, while it was projected to almost double in the developing countries (Bhagat et al., 2010). During recent decades, Bangladesh has experienced a rapid epidemiological transition from communicable to non-communicable diseases. Coronary heart disease (CHD), with myocardial infarction (MI) as its main manifestation, is a major cause of death in the country. However, there is limited reliable evidence about its determinants in this population (Chowdhury et al., 2015).

It is therefore important to assess the knowledge and attitude regarding the major risk factors of cardiovascular diseases among the adolescent students. This study also tries to analyze the underlying factors associated with the knowledge and attitude of the respondents so that risk factors can be reduced by implementing appropriate intervention measures.

\section{Materials and Methods}

A cross sectional study was conducted among women of some selected area of Dhaka city. The study took place after the approval of research proposal by Ethical Review Committee of State University of Bangladesh. Two Thana of Dhaka city were selected purposively. Mirpur thana was selected from DNCC \& Kamrangirchar from DSCC. 300 women were included from the study area according to inclusion \& exclusion criteria. Data collection was done between October \& November 2016 using a self administering questionnaire. At First an English version of the questionnaire was developed then it was translated into Bengali for field operation. The questionnaire was divided into 3 parts consisting of personal and socio-demographic characteristics, knowledge 
$\&$ attitude of participant regarding Cardiovascular Disease. Only fully completed questionnaires was selected to enter into the computer for final analysis. The analysis was carried out with SPSS (Statistical Package for Social Science), version 17.0. For statistical analysis, univariate, \& bi-variate analyses was calculated to relate the knowledge, attitude and practice and training components with other selected characteristics.

\section{Results}

\subsection{Socio-demographic characteristics of the study population}

The socio-demographic status of the respondents summarizes at a glance in Table 2. Majority of respondents were Muslim (99.00\%) with the mean (SD) age of respondents were 30.56 years. Table 1 shows that the highest frequency of the respondents is $40.7 \%$ were in the age group of within $25.34 .7 \%$ respondent was $26-35$ years group followed by 16.35 were $36-45$, very few respondent were 56 plus (3.4\%).

Table 1. Distribution of the respondents by age.

\begin{tabular}{lll}
\hline Age group & Frequency (n) & Percentage (\%) \\
\hline Under 25 & 122 & 40.7 \\
$26-35$ & 104 & 34.7 \\
$36-45$ & 49 & 16.3 \\
$46-55$ & 15 & 5.0 \\
$56-65$ & 8 & 2.7 \\
66 and Older & 2 & .7 \\
Total & $\mathbf{3 0 0}$ & $\mathbf{1 0 0 . 0}$ \\
\hline
\end{tabular}

Table 2. Socio-demographic characteristics.

\begin{tabular}{lll}
\hline Education & $\mathrm{n}$ & $\%$ \\
\hline Type & 33 & 11.0 \\
College & 51 & 17.0 \\
High School & 48 & 16.0 \\
Honors + & 20 & 6.7 \\
Illeterate & 148 & 49.3 \\
Primary & & \\
What is your marital status? & 1 & 3 \\
Divorced & 267 & 89.0 \\
Married & 26 & 8.7 \\
Single (never married) & 6 & 2.0 \\
Widow & & \\
What is your Family Size? & 103 & 34.3 \\
1-3 & 174 & 58.0 \\
4-6 & 19 & 6.3 \\
7-9 & 4 & 1.3 \\
$9+$ & & \\
Religion & 297 & 99 \\
Islam & 3 & 1 \\
Hindu & & \\
Occupation & 20 & 6.7 \\
Student & 51 & 17 \\
Service & 226 & 75.3 \\
Housewife & 3 & 1 \\
Business & & \\
\hline
\end{tabular}

Around half of the participant $(49.3 \%)$ were completed only primary education. $17 \%$ study participant were SSC passed, $16 \%$ respondent completed higher degree. 6.7\% participant were illiterate. Around 90\% (267) of the respondents were married. Remaining $8.7 \%$ (26) respondent were Unmarried, followed by $2 \%$ (6) were widowed \& Less than $1 \%$ (1) respondent were divorced. Major religion was Muslim (99\%) followed by Hinduism (1.8\%). The family size of most of the respondent (58\%) were 4-6, followed by $34.3 \%$ respondent 
had 1-3 member in her family. More than $6 \%$ respondent had 7-9 family member. Only $1.3 \%$ women's family size is $9+.75 .3 \%$ (226) respondent involved in only family activities, they had no formal professional experience. $17 \%$ were in service followed by student $6.7 \%$ and involve business $1 \%$ in local market. More than half of the participant 53.3\% ( $\mathrm{n}=160)$ monthly average income was 10001-20000 which indicated the economic condition of the study participant. Below 10\% respondent earned less than 10000 BDT. $7.7 \%$ of the respondent earned more than 50000 taka which indicated the good economic condition of the participant. $8.3 \%$ respondent monthly average income was BDT 40001-50000. Remaining $16 \%(\mathrm{n}=48)$ respondent monthly income was 20001-30000.

\subsection{Knowledge of Respondent about risk factor of CVD}

$63.7 \%$ respondent thinks that there is no relationship between the CVD \& family history of CVD. If Family member have history of high blood pressure there is no need to worry about approaching CVD. But only $6 \%$ people agree that there is a relationship between family histories of high blood pressure with CVD. $63.3 \%$ respondent gave positive feedback regarding obesity. Only $6.3 \%$ women have negative concept. In this study $45.7 \%$ respondent become confused during the answer of the question regarding high stress and CVD. $31.7 \%$ told that there is a relationship between high stress \& CVD. Rest of the respondent (22.7) say, there is no relationship between the high stress and CVD. Only $5.3 \%$ respondent denies the relationship between the two mentioned factor. $11 \%$ don't know the association so they did not have any valid answer of the question. Hyperlipidemia is recognized as a prominent risk factor for cardiovascular (CV) disease. $14.3 \%$ respondent don't know the relationship. 1\% percent told that now relationship existent between the two criteria. $97.3 \%$ women identifies smoking is one of the major causes of CVD. Only $2.3 \%$ told that smoking is not liable to CVD. However $99.7 \%$ women gave a answer regarding smoking. When it acts with other factors, it greatly increases risk. Smoking increases blood pressure, decreases exercise tolerance and increases the tendency for blood to clot.

Table 3. Level of knowledge about CVD.

\begin{tabular}{cllll}
\hline Serial & Statement & Yes & No & Don't Know \\
\hline $\mathbf{1}$ & Family history of CVD & 9.0 & 63.7 & 27.3 \\
$\mathbf{2}$ & Family history of high blood pressure. & 6 & 67 & 27 \\
$\mathbf{3}$ & Obesity & 63.3 & 6.3 & 30.3 \\
$\mathbf{4}$ & Stress & 31.7 & 22.7 & 45.7 \\
$\mathbf{5}$ & excessive consumption of oil & 83.7 & 5.3 & 11.0 \\
$\mathbf{6}$ & Hyperlipidemia & 84.7 & 1.0 & 14.3 \\
$\mathbf{7}$ & Smoking & 97.3 & 2.3 & .3 \\
\hline
\end{tabular}

The Table 3 shows the distribution of the respondent percentage based on their knowledge on Cardio vascular diseases. Total 10 items were prepared to assess the knowledge. Each item with correct response was carried out one mark. According to the scores, women are divided into poor, satisfactory, good \& excellent knowledge. Out of the 300 women, $56.67 \%$ had good knowledge, followed by $87(29 \%)$ had poor knowledge, 25(8.33\%) satisfactory knowledge \& 18(1.7\%) had excellent knowledge about Cardio vascular diseases.

\subsection{Attitude regarding major risk factors}

Level of attitude of women regarding cardio vascular disease also not up to the mark in comparison with other neighboring countries. Total 5 items were selected to assess the attitude level of the women which items were prepared to assess the attitude. Each item with correct response was carried out two mark. The attitude of women was categorized based on the scores as not favorable, Moderately Favorable, Favorable. The study shows that 56.67\% respondent are Moderately Favorable. According to the scores $29 \%$ respondents were Favorable followed by $14.33 \%$ do not have favorable attitude.

\section{Discussion}

There are many major factors which increase the risks of CVD. During the Literature review and later we have realize that the major factors are tobacco chewing/smoking, raised blood cholesterol level, high blood pressure, physical inactivity, overweight and obesity, excessive alcohol consumption, age, sex and heredity. Although cardiovascular diseases typically occur in middle age or later, risk factors are determined to a great extent by behaviors learnt in childhood and continued into adulthood. Throughout the world, these risks are starting to 
appear earlier. Findings of various studies worldwide suggested that adolescents lacked knowledge regarding the risk of cardiovascular diseases and did not perceive themselves at risk for cardiovascular diseases. Cardiovascular disease (CVD) is a class of diseases that involve the heart or blood vessels. In Bangladesh, This type of problem is familiar as Heart disease then CVD. Cardiovascular disease includes coronary artery diseases (CAD) such as angina and myocardial infarction (commonly known as a heart attack). Among the respondents around forty percent were in 18-25 years age group, followed by near about 34.7 percent were in below 26-35 years age group and below four percent were in more than 55 years age group (mean age $30.56 \pm 6.701$ years). Among the total respondent near about ninety nine percent were Muslim and rest of the respondent were Hindu. By level of education 49.3 percent were completed primary education, near about 17 percent were completed high school and below seven percent were not completed any formal education. By religion $99 \%$ of them were Muslim, only one percent were Hindu. By marital status $89 \%$ of the respondents were married, below ten percent of them were unmarried and near about two percent was widow. The present study revealed that among the respondent around 75 percent had not any single day professional working experience, they just involve themselves in home affairs activity and fostering children. Above $17 \%$ had working experience involved in various economic activities. Very few of them have business experience in local market.

\section{Conclusions}

Results of the study showed that good knowledge and positive attitude regarding the major risk factors of CVDs among women of Dhaka are unsatisfactory. Similarly findings also revealed that socio-demographic factors for the development of good knowledge and good knowledge for the development of positive attitude plays vital role. Due to the changing life style of Bangladesh people these days, they are more susceptible to life style related diseases like CVDs. Therefore to prevent CVDs, timely adoption of healthful habits is a must and the very age group for this is adolescence. Adolescent centered activities that can raise knowledge and develop positive attitude towards CVDs risk factors are strongly recommended so that healthful habits can be formed.

\section{Acknowledgement}

I would like to express my sincere gratitude to the Department of Public Health, School of Health Science, State University of Bangladesh for providing me an opportunity to conduct this research. I would also like to extend my profound gratitude to my research supervisor Dr. Shawkat Ara Haider for his nonstop guidance and meticulous editing of solecisms.

\section{Conflict of interest}

None of declare.

\section{References}

Mosca L, SM Grundy, D Judelson, K King, M Limacher, S Oparil, R Pasternak, TA Pearson, RF Redberg, SC Jr Smith, M Winston and S Zinberg, 1999. AHA/ACC scientific statement: consensus panel statement. Guide to preventive cardiology for women. American Heart Association/American College of Cardiology. J. Am. Coll. Cardiol., 33: 1751-1755.

Yusuf S, S Reddy, S Qunpuu and S Anand, 2001. Global burden of cardiovascular diseases-part i: general considerations, the epidemiologic transition, risk factors, and impact of urbanization. Circulation, 104: 27462753.

Manson JE and SS Bassuk, 2014. When is the use of aspirin for CVD prevention in women appropriate? Menopause, 21: 103-105.

Limbu YR, A Maskey, R Malla, MB KC, D Sharma and NK Shrestha, 2001. A study on cardiovascular disease pattern of admitted cases in newly emerged National Heart centre. Journal of Nepal Medical Association, 41: 284-288.

Kandpal V, MP Sachdeva and KN Saraswathy, 2016. An assessment study of CVD related risk factors in a tribal population of India. BMC Public Health, 16: 434.

Mendis S, 2014. Global status report on noncommunicable diseases 2014. World Health Organization.

Dhillon PK, P Jeemon, NK Arora, P Mathur, M Maskey, RD Sukirna and D Prabhakaran, 2012. Status of epidemiology in the WHO South-East Asia region: burden of disease, determinants of health and epidemiological research, workforce and training capacity. Int. J. Epidemiol., 41: 847-860.

World Health Organization, 2004. WHO publishes definitive atlas on global heart disease and stroke epidemic (The atlas of heart disease and stroke). World Health Organization, Geneva. 
Bhagat M, S Mukherjee, P De, R Goswami, S Pal, M Das and A Ghosh, 2010. Clustering of cardiometabolic risk factors in Asian Indian women: Santiniketan women study. Menopause, 17: 359-364.

Chowdhury R, DS Alam, II Fakir, SD Adnan, A Naheed, I Tasmin, MM Monower, F Hossain, FM Hossain, MM Rahman, S Afrin, AK Roy, M Akter, SA Sume, AK Biswas, L Pennells, P Surendran, RD Young, SA Spackman, K Hasan, E Harshfield, N Sheikh, R Houghton, D Saleheen, JM Howson, AS Butterworth; Cardiology Research Group, R Raqib, AA Majumder, J Danesh and E Di Angelantonio, 2015. The Bangladesh risk of acute vascular events (BRAVE) Study: objectives and design. Eur. J. Epidemiol., 30: 577-587. 